\title{
Optimisation of the determination of deoxynivalenol in wheat flour by HPLC and a comparison of four clean-up procedures.
}

\begin{abstract}
The determination of deoxynivalenol (DON) in wheat flour by liquid chromatography with photodiode array (PDA) detection was optimised. Response surface methodology (RSM) was used to determine the optimum chromatographic conditions for the determination of DON. The influence of three variables, acetonitrile $(\mathrm{ACN})$ volume in mobile phase $(9.5-24.5, \mathrm{v} / \mathrm{v})$, flow rate $(0.5-1.5 \mathrm{ml} \mathrm{min}-1)$ and wavelength $(215-221 \mathrm{~nm})$ on DON peak area was evaluated. The best separation was achieved using a symmetry column $(150 \times 3.9 \mathrm{~mm}$; particle size 5 $\mu \mathrm{m})$ by isocratic elution (1.0 ml min-1) and a mobile phase consisting of $\mathrm{ACN} /$ water in the ratio 17:83 (v/v). UV detection was performed at $218 \mathrm{~nm}$. Linear calibration curves were constructed in the concentration range 1-1000 ng ml-1. The detection limit measured as the signal-to-noise ratio (3:1) was $0.03 \mathrm{ng}$ ml-1. RSM results showed that the experimental data could be adequately fitted to a second-order polynomial model with multiple regression coefficients (R2) of 0.968 . The efficiency of four clean-up procedures for wheat flour extract was compared. Recovery of DON using a Mycosep \#225 column was highest with a value of $99 \%$, while that of Mycosep \#227 was $65 \%$. In contrast, DON recovery using immunoaffinity columns (IAC) and an Oasis ${ }^{\circledR}$ HLB column was only 53 and 42\%, respectively. The trueness of the method using the Mycosep \#225 column was established with a certified reference material CRM 379. The result obtained from three replicates was $0.66 \pm 0.04 \mu \mathrm{g} g-1$ and the certified value was $0.67 \mu \mathrm{g}$ g- 1 .
\end{abstract}

Keyword: Chromatography; HPLC; Clean-up; SPME; Clean-up; Affinity columns; Mycotoxins: Trichothecenes; Processed foods. 